\title{
Expression of SV40 Virus Large T Antigen by Recombinant Adenoviruses Activates Proliferation of Corneal Endothelium In Vitro
}

\author{
Sandy T. Feldman, ${ }^{*}$ Ruth Gjerset, ${ }^{*}$ Dennis Gately, ${ }^{*}$ Kenneth R. Chien, ${ }^{*}$ and James R. Feramisco ${ }^{* \$}$ \\ Departments of ${ }^{*}$ Ophthalmology, ${ }^{\ddagger}$ Medicine, and ${ }^{\S}$ Pharmacology, and Cancer Center School of Medicine, \\ University of California, San Diego, La Jolla, California 92093
}

\begin{abstract}
Infection with the Ad5-SVR4 virus was used to introduce the large $T$ antigen encoding region of the SV40 virus into bovine and human corneal endothelial cells. Expression of large $T$ antigen occurred in $40 \%$ of bovine corneal endothelial cells after a 24-h incubation time versus $12 \%$ after $8 \mathrm{~h}$ of incubation. By 48 $h$ after infection, almost all $(92.8 \%)$ bovine corneal endothelial cells expressed large $T$ antigen. Bovine and human corneal endothelial cells which expressed large $T$ antigen proliferated and the characteristic morphologic features of corneal endothelium were maintained. This method may enable growth of enough corneal endothelium to perform studies to elucidate the biochemical mechanisms involved in regulating endothelial cell function. (J. Clin. Invest. 1993. 91:1713-1720.) Key words: corneal endothelium $\cdot$ DNA synthesis $\bullet F$-actin $\bullet$ large $T$ antigen - recombinant viruses
\end{abstract}

\section{Introduction}

The corneal endothelium is an important cell layer for the maintenance of corneal clarity. Unlike endothelium of vascular origin, the corneal endothelium is derived from neural crest and lacks the characteristic marker for Factor VIII antigen. As humans age, corneal endothelial cells diminish in number and enlarge in size. Only rarely has proliferation been observed in the adult human cornea in vivo (1). In many mammalian species, a diminished central corneal endothelial density is observed in the adult animal owing to limited regeneration and enlargement of the eye $(2,3)$. The limited regeneration is insufficient to compensate for irreversible damage which may occur after inflammation or surgical trauma. The cornea therefore swells and opacifies.

Although of considerable clinical and scientific interest, relatively little is known about the biochemical processes which regulate the growth and differentiation of the corneal endothelium. Many investigators have reported success in overcoming the "in vivo" growth inhibition and have been able to culture

This work was presented in part at the Association for Research in Vision and Ophthalmology annual meeting, Sarasota, FL, 3 May 1991.

Address reprint requests to Dr. Sandy T. Feldman, Department of Ophthalmology (0946), Siley Eye Center, University of California, San Diego, La Jolla, CA 92093-0946.

Received for publication 8 July 1992 and in revised form 5 October 1992.

J. Clin. Invest.

(c) The American Society for Clinical Investigation, Inc.

$0021-9738 / 93 / 04 / 1713 / 08 \quad \$ 2.00$

Volume 91, April 1993, 1713-1720 human corneal endothelial cells $(\mathrm{HCE})^{1}$ in vitro by the addition of peptide growth factors to tissue culture medium, the use of young donor tissue, and/or coating the plasticware with extracellular matrix proteins (4-11). Maintenance of long-term cultures of corneal endothelium is difficult, largely due to the limited proliferative capacity and/or overgrowth by faster growing keratocytes (9). In addition, human samples must be pooled in order to obtain a sufficient quantity of cells for growth in culture. Bovine corneal endothelial cells (BCE), which have a higher proliferative activity both in vivo and in vitro than HCE, may also be overrun by keratocytes unless extreme care is taken. At the present time, there are no methods available for the culturing of corneal endothelium, making it difficult to perform studies to elucidate the biochemical mechanisms involved in regulating corneal endothelial cell proliferation and function.

To approach this problem, we have examined the consequences of SV40 large $\mathrm{T}$ antigen ( $\mathrm{T} \mathrm{Ag}$ ) on the growth properties of primary corneal endothelium (12). Large T Ag is capable of extending the lifespan of senescent human fibroblasts $(13,14)$ and immortalizing certain types of primary cells with the maintenance of differentiated functions (15-19).

In this study, we utilized a recombinant human adenovirus, which contains an SV40 large $\mathrm{T} \mathrm{Ag}$ transcriptional unit to achieve high efficiency of expression of large $\mathrm{T} \mathrm{Ag}$ into terminally differentiated primary cultures. In these infected cultures of $\mathrm{BCE}$, proliferation occurred in the majority of cells in the presence of low serum, in contrast to control uninfected cells that remained quiescent under these conditions. HCE, which displayed little proliferative capacity in vitro, entered the cell cycle and proliferated after infection. Passage of these cultures was possible 1 wk postinfection. In both BCE and HCE, the hexagonal morphology and the circumferential peripheral ring pattern of F-actin, characteristic features of these cells, were also maintained after expression of $\mathrm{T} \mathrm{Ag}$.

The development of a system to grow corneal endothelial cells should now enable the study of molecular events responsible for controlling the growth of corneal endothelium. In addition, the development of a method to engineer human corneal endothelial cells to proliferate may alter current surgical techniques of "corneal transplantation."

\section{Methods}

Cell culture. BCE were cultured primarily from eyes obtained from a slaughterhouse. Enzymatic digestion of corneal endothelial cells was accomplished by placing $50 \mu \mathrm{l}$ of $0.05 \%$ collagenase (Sigma Chemical

1. Abbreviations used in this paper: $\mathrm{BCE}$, bovine corneal endothelial cells; BrDU, bromodeoxyuridine; HCE, human corneal endothelial cells; MOI, multiplicity of infection; $\mathrm{T} \mathrm{Ag}, \mathrm{T}$ antigen. 


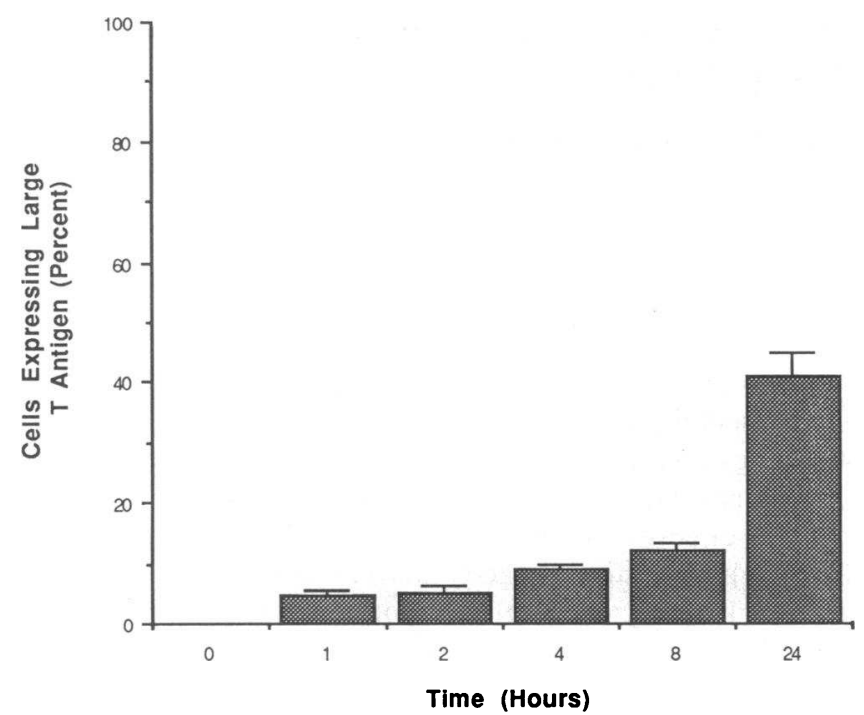

Figure 1. Percentage of $\mathrm{BCE}$ cells which express large $\mathrm{T} \mathrm{Ag}$ at varying incubation times.

Co., St. Louis, MO) onto the endothelial surface for $17 \mathrm{~h}$ at $37^{\circ} \mathrm{C}$. The cells were irrigated and plated onto $100-\mathrm{mm}$ culture dishes in $10 \mathrm{ml}$ of a 1:1 mixture of Ham's F12 and TC 199 (F99) supplemented with $15 \%$ FCS, glutamine $(3 \mathrm{mg} / \mathrm{ml})$, and the antibiotics, penicillin $(100 \mathrm{U} /$ $\mathrm{ml})$, streptomycin $(100 \mathrm{U} / \mathrm{ml})$. The cells were passaged once and plated onto coverslips for infection. These cells were deemed to be endothelial by well-established morphologic criteria under phase-contrast microscopy and by their F-actin staining pattern $(20,21)$.

$\mathrm{HCE}$ were isolated in the same fashion as described above from a 15-mo-old donor cornea (obtained from the San Diego Eye Bank) and pooled from the left and right corneas of a 66-yr-old donor unsuitable for human transplantation (donated by the San Diego Eye Bank). Cells were plated onto laminin $(10 \mu \mathrm{g} / \mathrm{ml}$ )-coated plasticware (Falcon Labware, Lincoln Park, NJ). The corneal endothelium of the young donor did not grow despite a 3-mo duration in culture. These primary cells and those freshly plated from the 66-yr-old donor were utilized for the human experiments described herein.

Preparation of adenovirus stocks. The recombinant adenovirus Ad5-SVR4 contains the large T Ag transcriptional unit cloned into the site of the early region genes, Ela and $\mathrm{Elb}(22)$. This virus is incapable of replicating by itself (23). However, replication of the Ad5-SVR4 virus can occur in 293 cells since they constitutively express Ela and E1b. The 293 cell line is a human embryonic kidney epithelial cell line transformed with a fragment of DNA from the Ad5 virus containing the early region that encodes for the Ela and Elb transcription factors (23). Additional virus was produced by lysing the infected 293 cells by freezing, thawing, and sonicating.

To assess the concentration of virus in stock solutions, dilutions of virus were added to 293 cells for $1 \mathrm{~h}$ at $37^{\circ} \mathrm{C}$, removed and overlain with $0.70 \%$ Noble agar in Earle's medium plus $2 \%$ serum. After 2 wk, plaques were counted.

Infection. These studies were performed in accordance with the policies of the Environmental Health and Safety Department at our institution. BCE (passage 1) were plated onto glass coverslips while HCE (primary) were plated onto one well of laminin-coated six-well plastic dish (Falcon Labware). Infection with the Ad5-SVR4 virus or a mock infection without virus was performed for various time intervals at $37^{\circ} \mathrm{C}$ in F99 with $2 \% \mathrm{FCS}$. The virus or medium for control wells was removed and replenished with F99 and 0 or $0.5 \%$ FCS.

Immunofluorescence: dual label analysis of large $T$ Ag and F-actin. Cells, plated onto uncoated glass coverslips, were fixed in $3.7 \%$ formal-

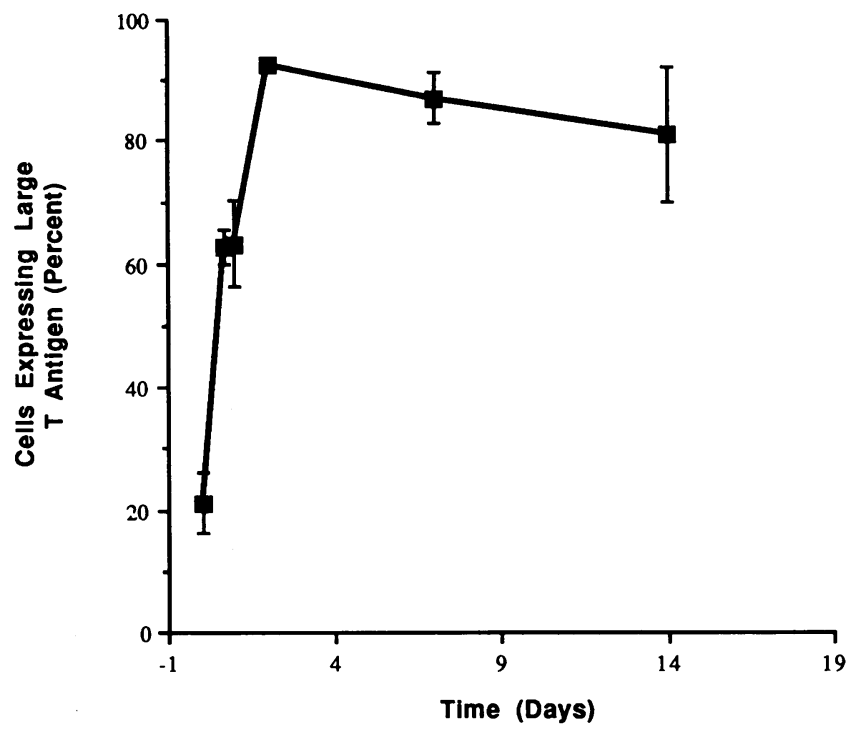

Figure 2. Percentage of $\mathrm{BCE}$ cells which express large $\mathrm{T}$ Ag at varying postincubation times. By $48 \mathrm{~h}$ postinfection, almost all cells express large $\mathrm{T} \mathrm{Ag}$. Growth of infected cells was selected for by using media with low amounts of serum $(0.5 \%)$.
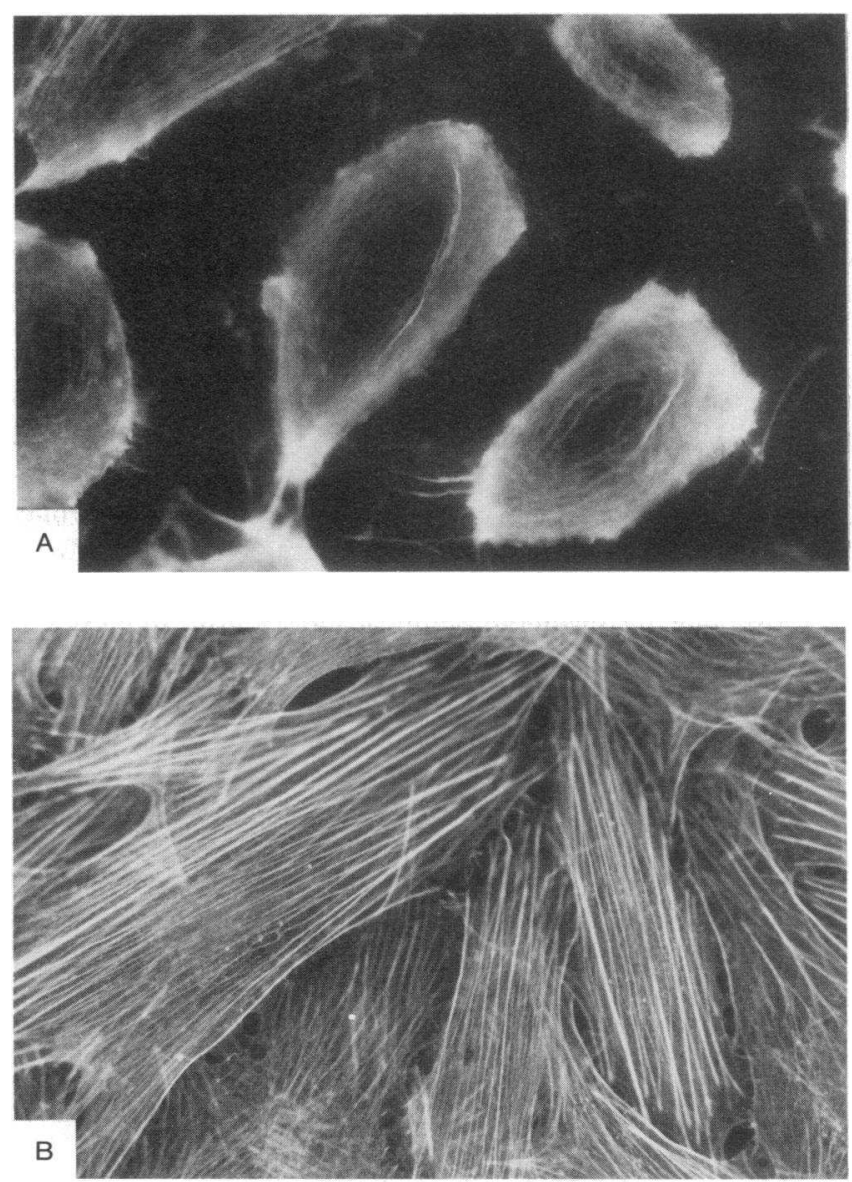

Figure 3. Shows the typical phalloidin appearance of $(A)$ BCE and (B) keratocytes. 

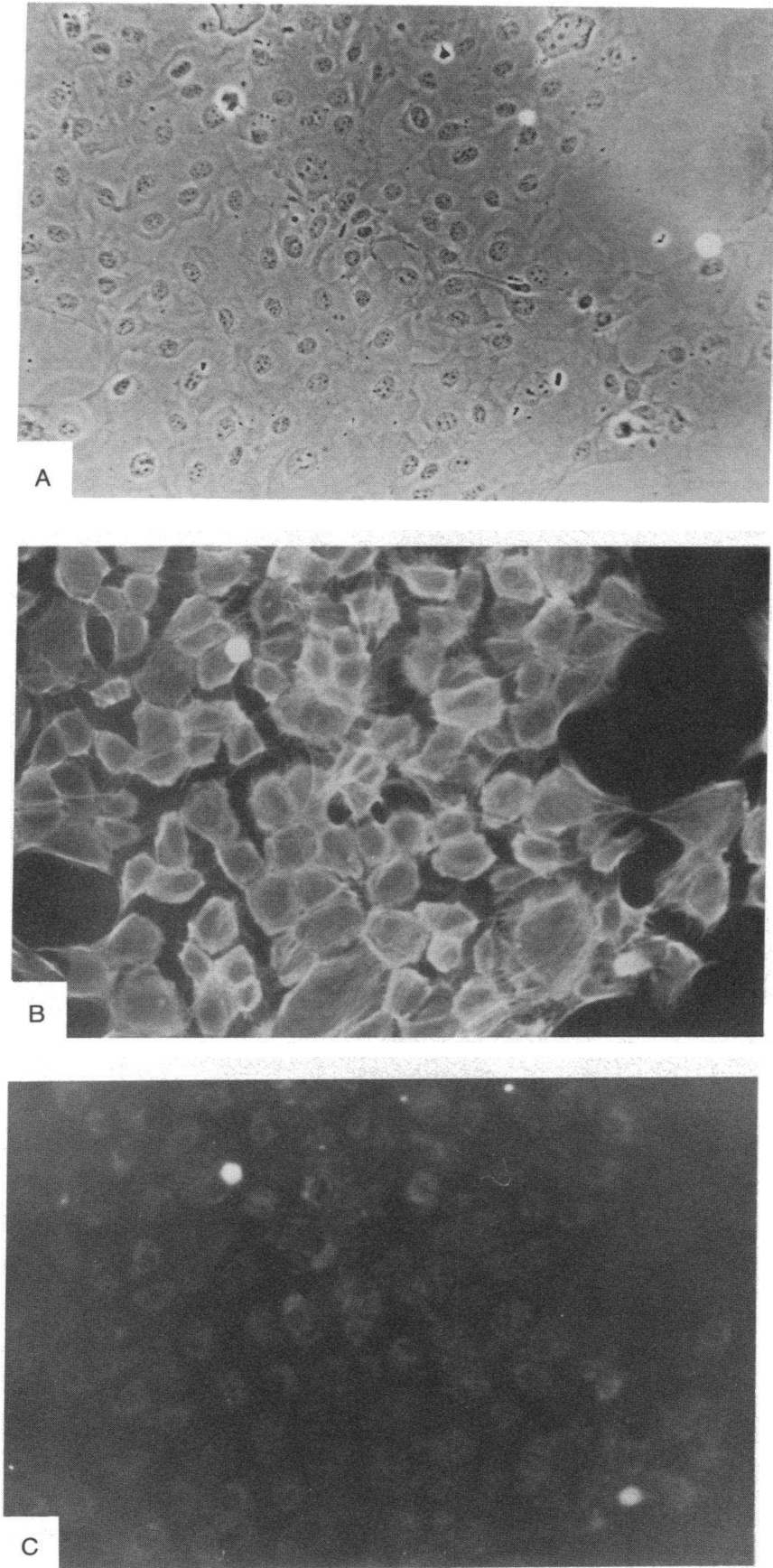

Figure 4. Phase-contrast and immunohistochemical appearance of uninfected BCE cells after staining for F-actin and large T Ag. $(A)$ $B C E$ in culture showed the typical polygonal structure as depicted in this phase-contrast photograph $(\times 200)$. $(B)$ The characteristic circumferential, peripheral ring pattern of $\mathrm{F}$-actin staining by fluorescein-labeled phalloidin was observed $(\times 200) .(C)$ As expected, BCE cells before infection showed no large $\mathrm{T}$ Ag expression, as indicated by the lack of nuclear staining $(\times 200)$.

dehyde in PBS and the membranes were permeabilized with $0.3 \%$ Triton X-100 in PBS. The coverslips were stained with anti-large T antibody (Oncogene Science Inc., Manhasset, NY) for $1 \mathrm{~h}$ at $37^{\circ} \mathrm{C},(1: 20$ dilution in PBS with $2 \mathrm{mg} / \mathrm{ml}$ BSA). After washing, the slips were incubated with a biotinylated goat antimouse (1:400 dilution, $1 \mathrm{~h}$ at $37^{\circ} \mathrm{C}$ ) to detect the prirnary antibody. Texas-Red conjugated strepavi- din (Vector Laboratories, Burlingame, CA) was used for visualization of the secondary antibody (1:100 dilution in PBS). In between all incubation steps, cells were washed with PBS containing $0.05 \%$ Nonidet-40 (NP-40) (Fisher Scientific Co., Fairlawn, NJ). The slips were then stained with fluorescein-conjugated phalloidin $(0.05 \mathrm{mg} / \mathrm{ml}$ in PBS with $1 \%$ DMSO, Sigma Chemical Co.) for $40 \mathrm{~min}$ at room temperature
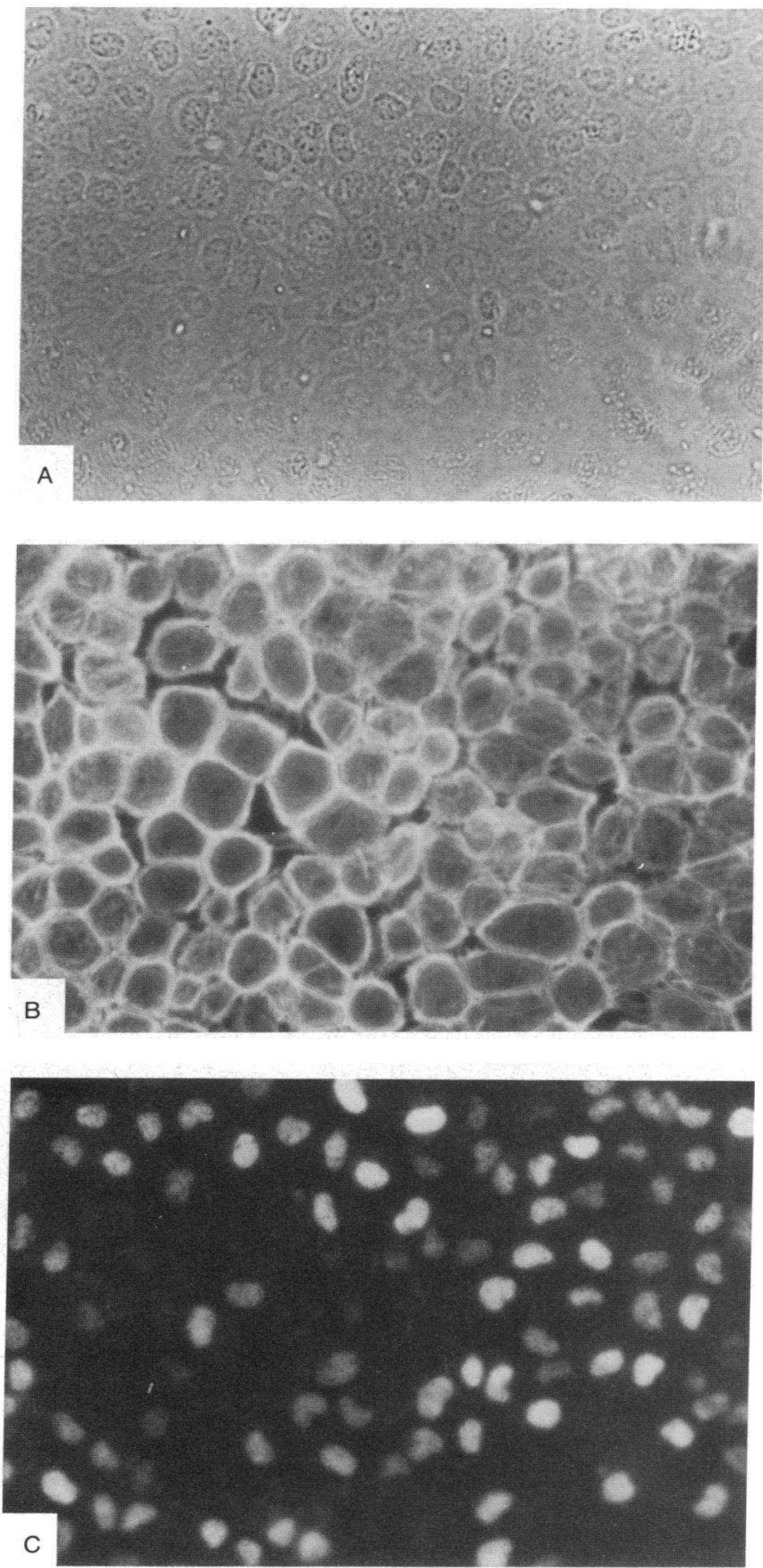

Figure 5. $(A)$ Phase-contrast appearance and ( $B$ and $C$ ) fluorescent staining patterns of BCE $2 \mathrm{wk}$ after infection. These pictures were taken from the same section of a dually stained specimen $(\times 400)$. $(A)$ The typical polygonal morphology is maintained. $(B)$ The morphological marker of F-actin staining is also preserved. $(C)$ Most cells in this specimen expressed large $\mathrm{T} \mathrm{Ag}$. 

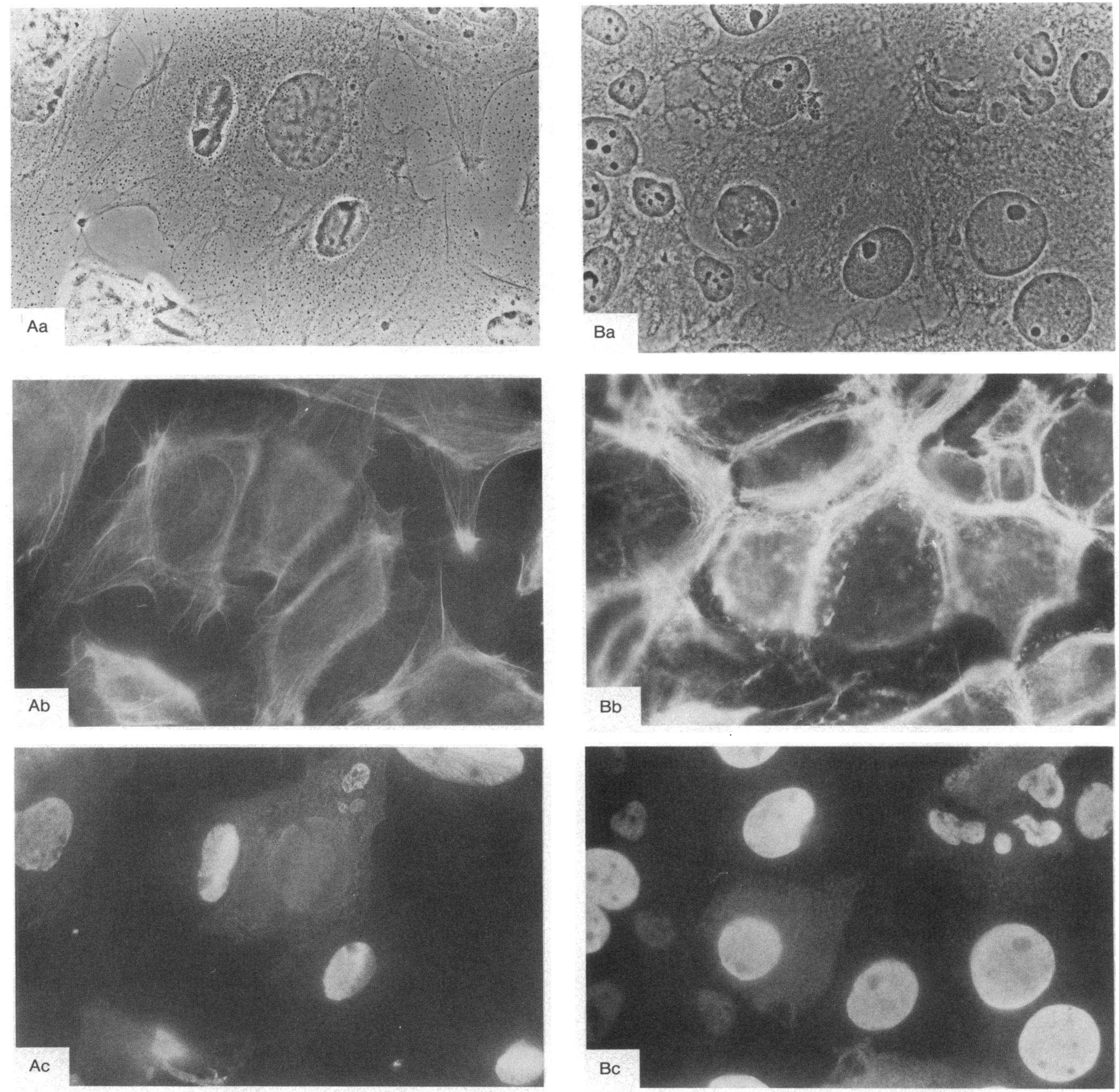

Figure 6. Phase-contrast appearance (a), F-actin staining pattern $(b)$, and large T Ag expression $(c)$ in HCE cells from $(A)$ 15-mo-old and $(B)$ 66-yr-old donors $(\times 630)$.

(24). Unbound phalloidin was rinsed off with PBS and the coverslips were mounted on microscope slides with gelvatol (Fisher Scientific Co.). Viewing and photography were performed on a Zeiss Axiophot fluorescent photomicroscope (Max Erb Instrument Co., West Burbank, CA) with T-MAX 400 film (Eastman Kodak Co., Rochester, NY) for fluorescent and Tech Pan film (Eastman Kodak Co.) for phase-contrast pictures.

DNA synthesis. Analysis of DNA synthesis was performed with cells plated onto coverslips as above, except that bromodeoxyuridine (BrDU, Amersham Corp., Arlington Heights, IL) was added to the growth medium for $24 \mathrm{~h}$. The cells were fixed with methanol $\left(-20^{\circ} \mathrm{C}\right)$ and incubated with the primary monoclonal antibody, anti-BrDU
(Amersham Corp.). The cells were next incubated with a second antibody, biotinylated goat anti-mouse antibody (Vector Laboratories; 1:400 dilution) for $1 \mathrm{~h}$ at $37^{\circ} \mathrm{C}$. Finally, the cells were incubated with streptavidin-Texas red, (1:100 dilution) $30 \mathrm{~min}$ at $37^{\circ} \mathrm{C}$. In between each incubation step, the slips were washed with PBS containing $0.05 \%$ NP-40. After the final incubation, the slips were washed, mounted onto microscope slides with gelvatol, and examined with a microscope as described above.

Cell number. BCE (infected or noninfected) were plated onto etched coverslips in duplicate at a density of $2 \times 10^{5}$ cells per $35-\mathrm{mm}$ well. 10 fields of each coverslip were counted and photographed by phase contrast microscopy at 1,2 , and $5 \mathrm{~d}$ after plating. 

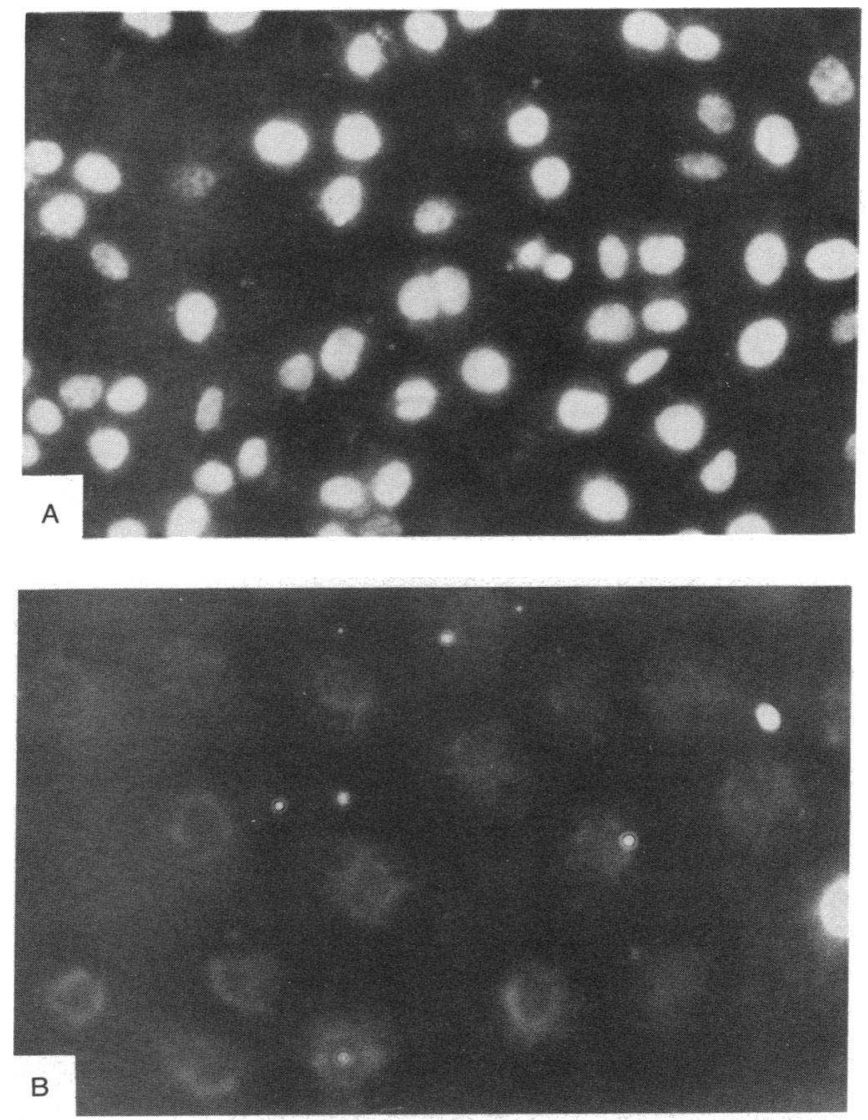

Figure 7. $(A)$ BCE cells show marked DNA synthesis 1 wk postinfection. $(B)$ Control cells that have been maintained in the low serum media are quiescent.

\section{Results}

To determine the optimal conditions for expressing large $\mathrm{T} \mathrm{Ag}$ in $\mathrm{BCE}$, cultures of $\mathrm{BCE}$ placed onto glass coverslips were infected with varying amounts of the Ad5-SVR4 virus. Under these conditions, a multiplicity of infection (MOI) of 50 was found to be suitable for these cells and was therefore used in all subsequent experiments. We next varied the time of infection and assayed for large T Ag expression by immunofluorescence. The recombinant adenovirus was incubated with BCE for varying time periods. The virus was removed and replaced with fresh media. $24 \mathrm{~h}$ after removal of the virus, the cells were harvested to examine for large $\mathrm{T} \mathrm{Ag}$ expression as assessed by immunofluorescence. Cells expressing large T Ag showed positive nuclear staining. After a 24 -h incubation time, $40 \pm 3.9 \%$ of the cells expressed large $\mathrm{T} \mathrm{Ag}$, whereas after $8 \mathrm{~h}$ of incubation with virus, only $12.2 \pm 1.1 \%$ of cells expressed large $\mathrm{T} \mathrm{Ag}$ (Fig. 1). A timepoint greater than $24 \mathrm{~h}$ was not tested since these cells normally divide within $24 \mathrm{~h}$, a problem which would have made interpretation of the data difficult.

To determine the postinfection time required for maximal expression of large $\mathrm{T} \mathrm{Ag}$, a separate time course experiment was performed. For these experiments, cells were placed in F99 and $2 \%$ FCS and the AD5-SR4 virus at an MOI of 50 was added for $24 \mathrm{~h}$. After $24 \mathrm{~h}$ the cells were replaced with F99 and
$15 \%$ FCS. The cells were harvested at $0,17,24$, and $48 \mathrm{~h}$ and 1 and 2 wk postinfection for immunostaining for large $\mathrm{T} \mathrm{Ag}$. The results of this timecourse are shown in Fig. 2. By $48 \mathrm{~h}$ postincubation, $92.3 \pm 1.1 \%$ of the cells expressed large $\mathrm{T} \mathrm{Ag}$. The positively expressing cells continued to express large $\mathrm{T}$ Ag up to 2 wk after infection.

Because cell specific markers have not yet been identified which are unique to corneal endothelium, well-established morphologic criteria were examined to assess the differential state of the cells expressing large $T$ antigen. A characteristic hexagonal shape and circumferential peripheral ring pattern of $F$-actin staining have been seen in human, rabbit, bovine corneal endothelium (Fig. $3 A)(20,21)$, as these morphological characteristics are not seen in keratocytes isolated from the cornea (Fig. $3 B$ ). We used this morphological staining pattern with phalloidin as a putative marker of the differentiated state of corneal endothelium.

As shown in Fig. 4, before infection, BCE cells grown in $15 \%$ FCS have the characteristic ring pattern and as expected, do not express $\mathrm{T}$ Ag. BCE were then either infected with the recombinant virus for $24 \mathrm{~h}$ or mock-infected and then grown in F99 medium with low serum $(0.5 \%)$. Dual staining for large $T$ $\mathrm{Ag}$ and phalloidin was performed on each sample. 2 wk after viral infection, $81.0 \pm 11 \%$ of cells expressed $\mathrm{T} \mathrm{Ag}$ and still maintained their normal morphology (Fig. 5).

Although the previous studies indicate the feasibility of expressing $\mathrm{T} \mathrm{Ag}$ in bovine cells with this recombinant virus, our ultimate goal was to adopt this system to human cells. Accordingly, HCE obtained from a 15-mo-old donor and newly prepared pooled cultures of the right and left corneas of a 66-yr-old donor that were isolated enzymatically and plated onto laminin-coated plastic dishes were infected with the recombinant virus using the same parameters: i.e., an MOI of 50 and a 24-h infection time. $1 \mathrm{wk}$ after the infection, most of the infected HCE expressed $\mathrm{T} \mathrm{Ag}$ and also retained their normal phalloidin staining pattern (Fig. 6, $A b$ and $B b$ ).

The effect of large $\mathrm{T} \mathrm{Ag}$ expression on DNA synthesis of

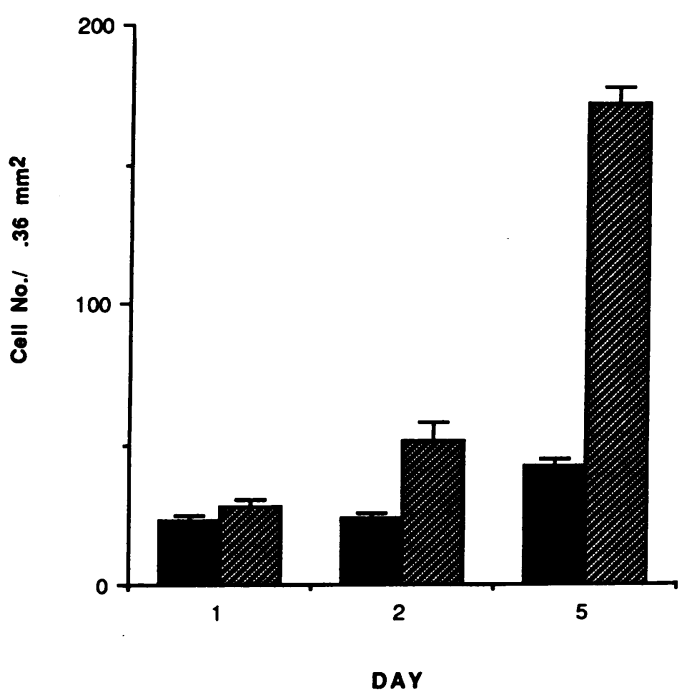

Figure 8. Bar graph comparing the growth of BCE versus infected $\mathrm{BCE}$ expressing large $\mathrm{T} \mathrm{Ag}$ at 1,2 , and $5 \mathrm{~d}$ after plating. 
corneal endothelium was measured. Infected or mock-infected cells were grown in low serum media $(0.5 \%$ FCS $)$ for $1 \mathrm{wk}$ and the percentage of cells undergoing DNA synthesis was determined by immunofluorescence. Cells undergoing DNA synthesis incorporated BrDU and showed nuclear staining. $4.2 \pm 1.3 \%$ of the starved, mock-infected cells stained positively as compared with $73.7 \pm 3.0 \%$ of the infected cells (Fig. 7).

To determine the effect of large $\mathrm{T}$ Ag expression on corneal endothelial cell proliferation, infected or noninfected cells were plated onto etched coverslips and counted at 1,2 , and $5 \mathrm{~d}$ after plating. The number of $\mathrm{BCE}$ expressing large $\mathrm{T} \mathrm{Ag}$ were far greater than the number of noninfected cells (Fig. 8). Fig. $9 \mathrm{~A}-$ $D$ depicts phase-contrast microscopy of the large $\mathrm{T}$ Ag expressing and nonexpressing cells at 2 and $5 \mathrm{~d}$, respectively.

\section{Discussion}

The lack of a uniformly successful method for culturing corneal endothelium has hindered the study of the biochemical characteristics and molecular mechanisms involved in regulating terminal differentiation, cellular growth, and prolifera-
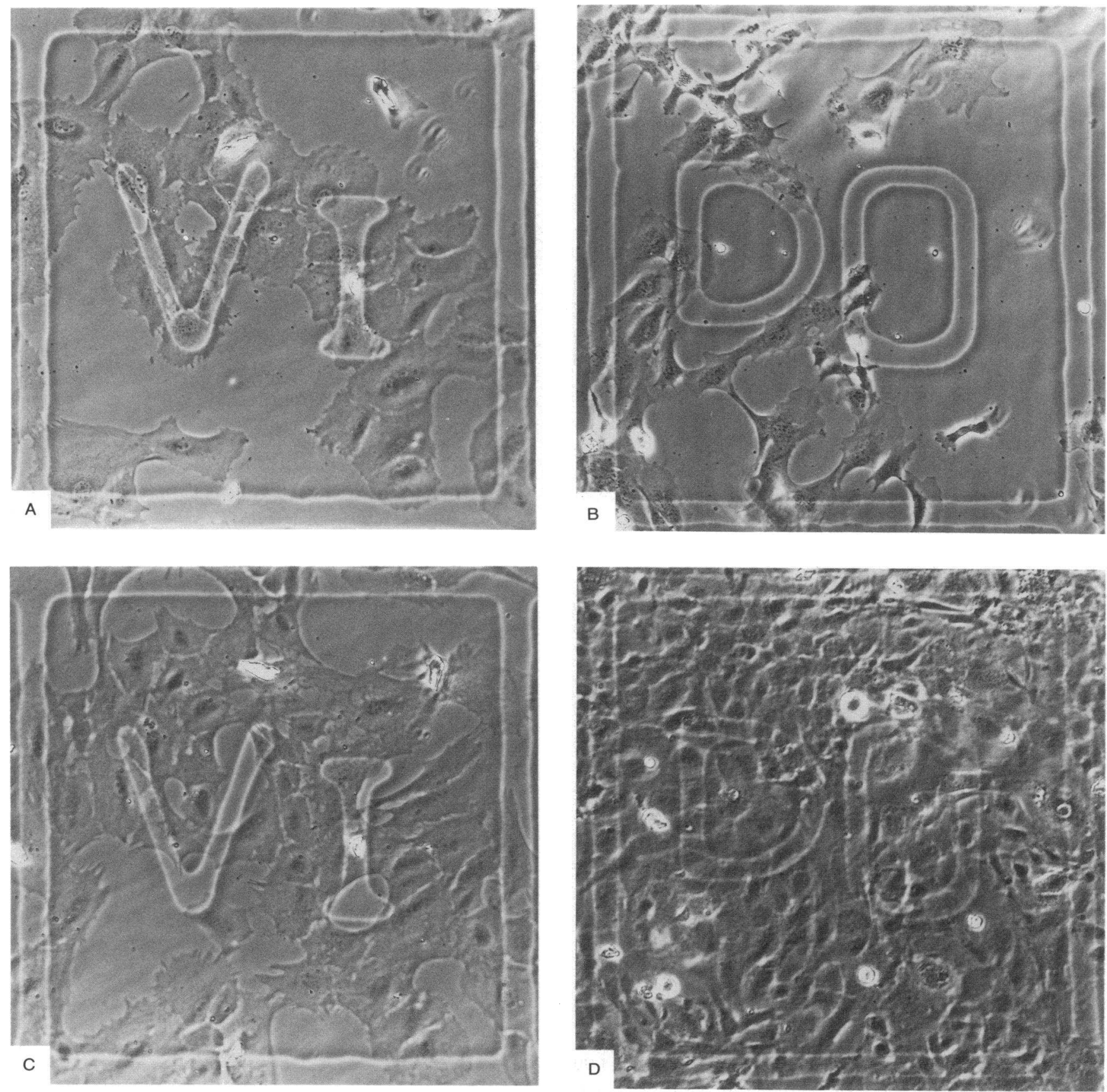

Figure 9. Phase-contrast photographs of $(A) \mathrm{BCE}$ and $(B)$ infected BCE at $2 \mathrm{~d}$ and $(C) \mathrm{BCE}$ and infected $(D) \mathrm{BCE}$ at $5 \mathrm{~d}$ after plating. 
tion of this important cell type. In this study, we demonstrate that introduction of the large $\mathrm{T} \mathrm{Ag}$ allows for the growth of corneal endothelium of bovine and human origin even in media containing low serum. While many studies demonstrated the ability to culture human corneal endothelium in vitro, numerous growth factors and/or extracellular matrix proteins were required (4-11) and, sometimes, pooling of the corneas was necessary. The morphology of corneal endothelium may in fact change with the addition of growth factors, such as epidermal growth factor (21). Even then, long-term passage was difficult as corneal endothelium senesced in culture or were overtaken by the few contaminating faster-growing keratocytes (9).

Our study employed a different approach towards creating a potentially useful culturing system for corneal endothelium. We utilized a recombinant, adenoviral vector which contained the large $\mathrm{T} \mathrm{Ag}$ transcriptional unit cloned into the site of the early region genes, which normally encodes for the transcriptional factors $\mathrm{E} 1 \mathrm{a}$ and $\mathrm{E} 1 \mathrm{~b}(22,23)$. A viral vector was utilized as this generally yields a higher efficiency of stable transfer of the DNA than does transfection.

Large $\mathrm{T} \mathrm{Ag}$ is a protein produced by the SV40 virus that has been shown to immortalize many types of primary cells (16$19)$ and to cause reentry of senescent cells into the cell cycle $(13,14)$. Cardiac myocytes, like corneal endothelium, do not proliferate past the neonatal period and undergo hypertrophy with ageing (25). Expression of large $\mathrm{T} \mathrm{Ag}$ in cardiac muscle cells enabled proliferation with maintenance of the differentiated features: beating in response to $\beta$-adrenergic agents and expression of the myosin light chain (19). We therefore chose to utilize the recombinant adenoviral vector Ad5-SVR4 which contains the genes for the large $\mathrm{T} \mathrm{Ag}$ to infect corneal endothelial cells. This virus is amphotrophic for infection but is incapable of replicating without the Ela and Elb transcription factors.

Thus, the Ad5-SVR4 vector was capable of infecting both $\mathrm{HCE}$ and $\mathrm{BCE}$ in vitro without causing cytotoxic effects. The dilution of virus of our stocks that produced infection was similar to that previously reported (19). $\mathrm{T} \mathrm{Ag}$ was expressed in both HCE and BCE. A time course for viral incubation in BCE revealed that an incubation of $24 \mathrm{~h}$ was necessary for optimal expression of large $\mathrm{T} \mathrm{Ag}$. This gave a rate of infection high enough such that selection of the large $\mathrm{T}$ Ag expressing cells by growth in low serum media was possible.

In $\mathrm{BCE}, 92 \%$ of cells expressed large $\mathrm{T} \mathrm{Ag}$ by $48 \mathrm{~h}$ after infection. These cells continued to express large $\mathrm{T} \mathrm{Ag}$ for at least $2 \mathrm{wk}$. Whether the expression is stable over the long term was not addressed in this study; however, we have been able to maintain these cells in culture for more than $1 \mathrm{yr}$.

The extended growth potential of these cells is consistent with previous studies showing that large T Ag can induce proliferation in other types of human cells, including senescent cells $(18,19)$. As large $\mathrm{T} \mathrm{Ag}$ is known to complex with both retinoblastoma and p53 tumor suppressor genes (26-28), it is possible that these complexes are responsible for the observed induction of proliferation in the CE. Further studies are underway to elucidate the roles of p53 and retinoblastoma in corneal endothelial cell proliferation.

The differential hexagonal morphology and staining pattern of F-actin was indistinguishable in infected or uninfected cells, suggesting that expression of large $\mathrm{T} \mathrm{Ag}$ does not result in loss of the characteristic morphological features of corneal endothelium. This suggests that the use of large $\mathrm{T} \mathrm{Ag}$ to induce growth of corneal endothelium may prove helpful as a method for either in situ or in vitro growth procedures. While large $T$ $\mathrm{Ag}$ is known to be an oncogene, we would expect that loss of differentiated features and transformation would occur more commonly with long term expression. This may be species dependent as well $(15,29,30)$. The creation of long-term cultures of corneal endothelial cells by perhaps using conditional expression of large $\mathrm{T} \mathrm{Ag}$ may avoid this problem and thereby, will enable us to investigate the biochemical mechanisms involved in cellular proliferation and growth.

\section{Acknowledgments}

This study was supported in part by Physician Scientist Award No. AG000353 from the National Institutes of Health.

\section{References}

1. Laing, R. A., L. Neubauer, S. S. Oak, H. L. Kayne, and H. M. Leibowiz. 1984. Evidence for mitosis in the adult corneal endothelium. Ophthalmology. 91:1129-1134.

2. Bahn, C. F., R. M. Glassman, D. K. MacCallum, J. H. Lillie, R. F. Meyer, B. J. Robinson, and N. M. Rich. 1986. Postnatal development of corneal endothelium. Invest. Ophthalmol. Visual Sci. 27:44-51.

3. Van Horn, D. L. and R. A. Hynduik. 1975. Endothelial wound repair in primate cornea. Exp. Eye. Res. 21:113-124.

4. Mannagh, J. and R. A. Irving. 1974. Human corneal endothelium: growth in tissue culture. Arch. Ophthalmol. 74:847-849.

5. Baum, J., R. Niedra, C. Davis and B. Yue. 1979. Mass culture of human corneal endothelial cells. Arch. Ophthalmol. 97:1136-1140.

6. Nayak, S. K., and P. S. Binder. 1984. The growth of endothelium from human cornea rims in tissue culture. Invest. Ophthalmol. Visual Sci. 25:12131216.

7. Hsieh, P. and J. Baum. 1985. Effects of fibroblastic and endothelial extracellular matrices on corneal endothelial cells. Invest. Ophthalmol. Visual Sci. 26:457-463.

8. Pistsov, M. Y., E. Y. Sadovnikova, and S. M. Danilov. 1988. Human corneal endothelial cells: isolation, characterization and long-term cultivation. Exp. Eye Res. 47:403-414.

9. Engelmann, K. and P. Friedl. 1989. Optimization of culture conditions for human corneal endothelial cells. In Vitro Cell. Dev. Biol. 25:1065-1072.

10. Yue, B. Y., J. Sugar, J. E. Gilboy, and J. L. Elvart. 1989. Growth of human corneal endothelial cells in culture. Invest. Ophthalmol. Visual Sci. 30:248-253.

11. Samples, J., S. K. Nayak, and P. S. Binder. 1991. Propagation of human corneal endothelium in vitro effect of growth factors. Exp. Eye Res. 52:121-128.

12. Livingston, D. M., and M. K. Bradley. 1987. The simian virus 40 large T antigen: a lot packed into a little. Mol. Biol. Med. 4:63-80.

13. Mitsui, Y., and K. Hirokawa. 1984. Mechanisms of cellular aging. Cell. Struct. Funct. Suppl. 9:27-33.

14. Gorman, S. D., and V. J. Cristofalo. 1985. Reinitiation of cellular DNA synthesis in BrdU-selected nondiving senescent WI-38 cells by simian virus 40 infection. J. Cell. Physiol. 125:122-126.

15. Petit, C. A., M. Gandes, and J. Feunteun. 1983. Immortalization of rodent embryo fibroblast by SV40 in maintained by the A gene. Virology. 127:74-82.

16. Woodworth, C. D., and H. C. Isom. 1987. Regulation of albumin gene expression in a series of rat hepatocyte cell lines immortalized by simian virus 40 and maintained in chemically defined medium. Mol. Cell. Biol. 3740-3748.

17. Coca Prado, M., and M. B. Wax. 1986. Transformation of human ciliary epithelial cells by simian virus 40 . Induction of cell proliferation and retention of B2 adrenergic receptors. Proc. Natl. Acad. Sci. USA. 83:8754-8758.

18. Woodworth, C. D., T. Secott, and H. C. Isom. 1986. Transformation of rat heptocytes by transfection with simian virus 40 DNA to yield proliferating differentiated cells. Cancer Res. 46:4018-4026.

19. Sen, A., P. Dunnman, S. A. Henderson, R. D. Gerard, and K. R. Chien. 1988. Terminally differentiated neonatal rat myocardial cells proliferate and maintain specific differentiated functions following expression of SV40 Large T antigen. J. Biol. Chem. 263:19132-19136.

20. Gordon, S. R. 1990. Changes in extracellular matrix proteins and actin during corneal endothelial growth. Invest. Ophthalmol. Visual Sci. 31:94-101. 
21. Raymond, G., M. Jumblatt, S. Bartels, and A. Neufeld. 1986. Rabbit corneal endothelial cells in vitro: effects of EGF. Invest. Ophthalmol. Visual Sci. 27:474-479.

22. Van Doren, K., and Y. Gluzman. 1984. Efficient transformation of human fibroblasts by adeno-virus-simian virus 40 recombinants. Mol. Cell. Biol. 4:1653-1656.

23. Graham, F. L., J. Smiley, W. C. Russell, and R. Nairn. 1977. Characteristics of a human cell line transformed by DNA from human adenovirus type $5 . J$ Gen. Virol. 36:49-72.

24. Wulf, E., A. Deboben, F. A. Bautz, H. Faulstich, and T. H. Wieland. 1979. Fluorescent phallotoxin, a tool for the visualization of cellular actin. Proc. Natl. Acad. Sci. USA. 76:4498-4502.

25. Rumyantsev, P. P. 1977. Interrelations of the proliferation and differentiation process during cardiac myogenesis and regeneration. Int. Rev. Cytol. 51:187-273.
26. DeCaprio, J. A., J. W. Ludlow, J. Figge, J. Y. Shaw, C. M. Huang, W. H. Lee, E. Marsillo, E. Pauca, and D. M. Livingston. 1988. SV40 large tumor antigen forms a complex with the product of the retinoblastoma susceptibility gene. Cell. 54:275-283.

27. McCormick, F., R. Clark, E. Harlow, and R. Tjian. 1981. SV40 T antigen binds specifically to a cellular p53 protein in vitro. Nature (Lond.). 292:63-65.

28. Peden, K. W., A. Srinivasan, J. M. Farber, and J. M. Pipas. 1989. Mutants with changes within or near a hydrophobic region of simian virus 40 large tumor antigens are defective for binding cellular protein p53. Virology. 168:13-31.

29. Land, H., L. F. Parada, and R. A. Weinberg. 1983. Tumorigenic conversion of primary embryo fibroblasts requires at least two cooperating oncogenes. Nature (Lond.). 304:596-602.

30. Jat, P. S., and P. A. Sharp. 1989. Cell lines established by atemperature sensitive simian virus 40 large $T$ antigen gene are growth restricted at the nonpermissive temperature. Mol. Cell. Biol. 9:1672-1680. 